\title{
A Rare Presentation of a Rare Disease: Pulmonary Lymphomatoid Granulomatosis
}

\author{
Ghulam Rehman Mohyuddin, ${ }^{1}$ Fatima Sultan, ${ }^{1}$ and Ghulam Khaleeq ${ }^{2}$ \\ ${ }^{1}$ Department of Internal Medicine, Geisinger Medical Center, 100 North Academy Avenue, Danville, PA 17822, USA \\ ${ }^{2}$ Division of Pulmonary and Critical Care, Geisinger Medical Center, 100 North Academy Avenue, Danville, PA 17822, USA
}

Correspondence should be addressed to Ghulam Khaleeq, gkhaleeq1@geisinger.edu

Received 23 September 2012; Accepted 30 October 2012

Academic Editors: H. Niwa, M. Takao, and N. Yoshimura

Copyright ( 2012 Ghulam Rehman Mohyuddin et al. This is an open access article distributed under the Creative Commons Attribution License, which permits unrestricted use, distribution, and reproduction in any medium, provided the original work is properly cited.

\begin{abstract}
A 70-year-old female presented with a 4-week history of dry cough and wheezing. Chest radiograph showed a $10.5 \mathrm{~cm}$ masslike density in the anterior mediastinum which had not been previously visualized. Computed tomography scan (CT) of the chest showed a right hilar mass encasing and narrowing right upper lobe bronchus and right mainstem bronchus and secondary atelectatic changes. Biopsy was consistent with a diagnosis of lymphomatoid granulomatosis Grade 3 . She responded well clinically and radiologically to therapy. Lymphomatoid granulomatosis is a rare EBV-associated disorder which is considered a lymphoproliferative disease. The most common radiographic feature is multiple lung nodules. An isolated hilar mass is an exceptionally rare presentation of this rare disease.
\end{abstract}

\section{Introduction}

Lymphomatoid granulomatosis is a rare EBV-associated disorder which is considered part of the spectrum of lymphoproliferative disorder [1]. Commonly presenting as multiple lung nodules, on occasion atypical radiographic patterns can be observed. We report one such highly unusual presentation.

\section{Case}

A 70-year-old female presented with a 4-week history of dry cough and wheezing. Her review of systems was unremarkable. She had no preexisting lung disease and the only medications she was taking were her antihypertensives. She had no history of alcohol use, smoking, drug abuse, or any occupational hazards. Her past medical and surgical histories were significant for hypertension, migraines, and anxiety disorder.

Physical examination was significant for decreased air entry on the right side of the chest. She was hypoxemic on room air requiring 2 liters of nasal cannula oxygen to keep a saturation of 92 percent. Systemic examination was otherwise unremarkable.

Her complete blood counts and metabolic panel were normal. Her lactate dehydrogenase level was 215 IU/L (normal range 105-333 IU/L). Chest radiograph showed a $10.5 \mathrm{~cm}$ mass-like density in the anterior mediastinum which had not been previously visualized. Computed tomography scan (CT) of the chest showed a right hilar mass encasing and narrowing right upper lobe bronchus and right mainstem bronchus. Secondary atelectatic changes were also observed (Figure 1). Bronchoscopy further confirmed these findings (Figure 3).

The biopsy showed necrotic tissues, and infiltration with histiocytes and atypical lymphoid cells (Figures 4 and 5). Special stains demonstrated that the atypical population was characterized by CD20 and PAX8 positive B cells. CD3 markers highlighted a lesser T-cell infiltrate. An Epstein-Barr virus in situ hybridization procedure demonstrated EBV in the filtrate. Acid fast and fungal stains were negative.

This was consistent with a diagnosis of lymphomatoid granulomatosis Grade 3. She was referred to the oncology service, where she underwent a PET scan and a bone 


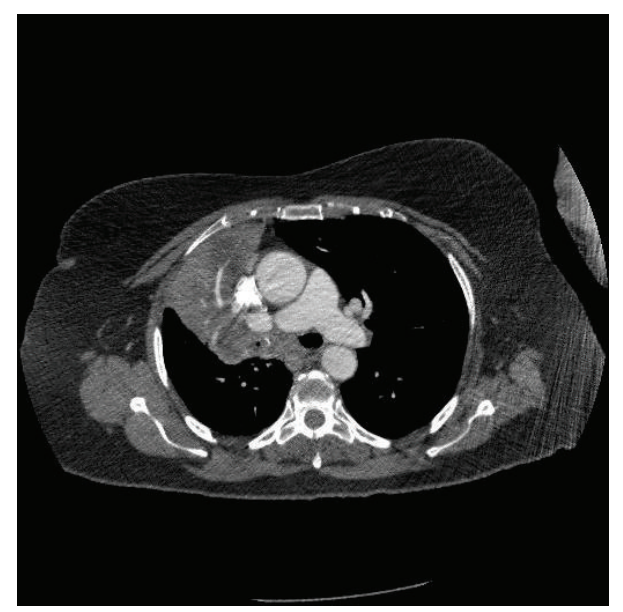

Figure 1: CT scan showing a right hilar mass which encases and narrows the right upper lobe bronchus and the right main stem bronchus.

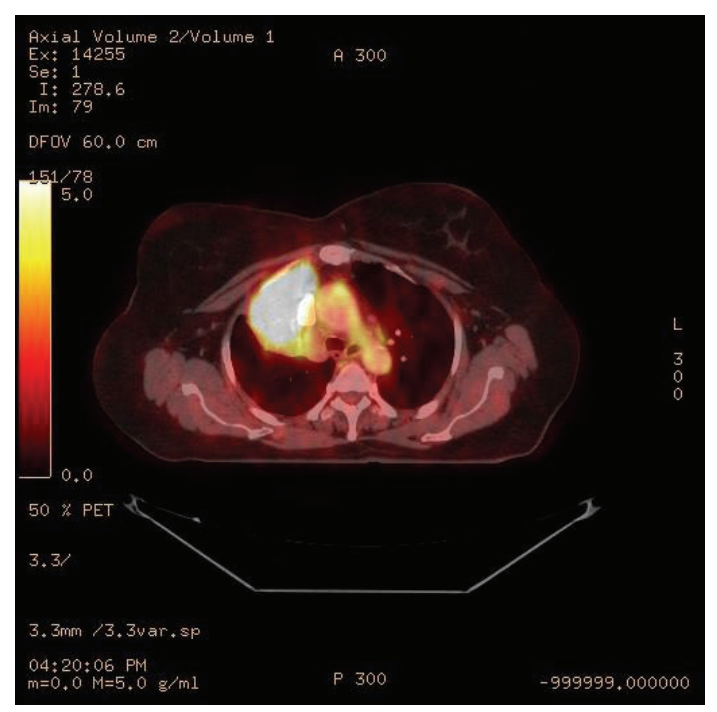

FIGURe 2: PET SCAN image showing FDG avid large right upper lobe heterogeneous low-density mass causing mass effect upon the main stem bronchus.

marrow biopsy (Figure 2). She was given 6 cycles of the R$\mathrm{CHOP}$ regimen which was then followed by Involved Field Radiation Therapy (IFRT). A drastic clinical and radiological improvement was noted.

\section{Discussion}

As seen in our patient, the histological diagnosis of PLG includes a triad of polymorphic lymphoid infiltrates, transmural infiltration of arteries and veins by lymphoid cells "angiitis", and focal areas of necrosis within the lymphoid infiltrates [2]. A histopathological grading from Grade 1 to 3 exists, based on the atypical EBV-positive B cells present [3] .

PLG is seen in various immunodeficiency states, such as AIDS, Wiskott-Aldrich syndrome, post-transplantation

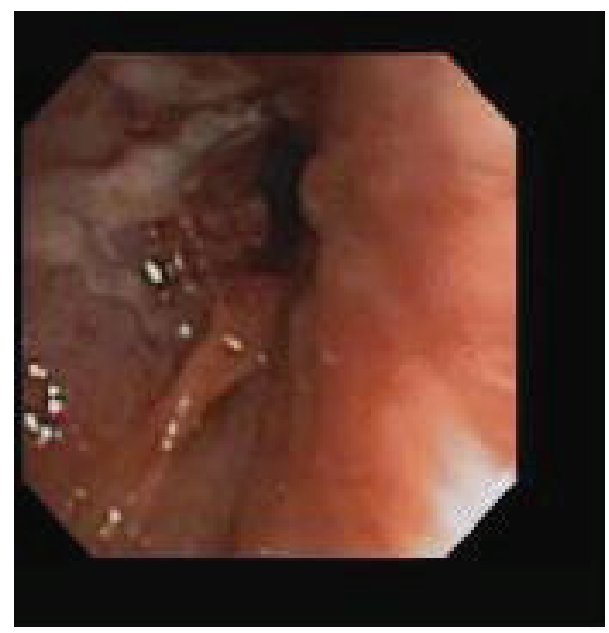

FIGURE 3: Bronchoscopy showing bronchial mucosal abnormalities with whitish plaques and mucosal inflammation and swelling obstructing the RUL bronchus.

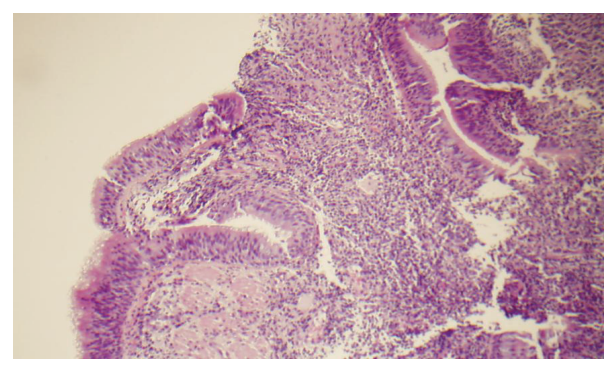

FIGURE 4: Bronchial biopsy reveals dense infiltration of atypical lymphocytes and histiocytes.

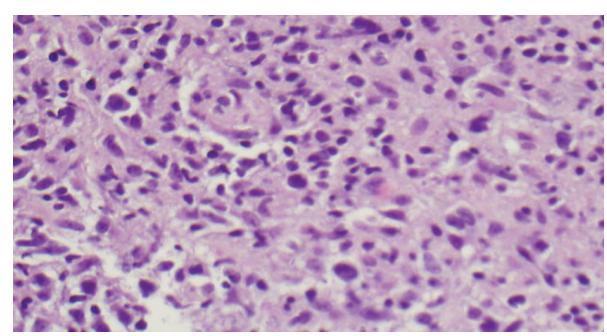

FIGURE 5: High power view of bronchial biopsy. The small to large atypical lymphocytes have pleomorphic, hyperchromatic nuclei, and distinct nucleoli. Scattered plasma cells and histiocytes are present.

immunodeficiency [4], and use of immunosuppressant medications [5].

PLG generally presents between the ages of 30 and 50, men being most often affected [6]. The lungs are most commonly involved, followed by the skin and the central nervous system [3].

Common findings include cough, fever, malaise, and weight loss [7]. Skin involvement manifests as rash, ulceration, or subcutaneous nodules. Neurologic involvement can manifest as ataxia, cranial nerve abnormalities, and peripheral neuropathy $[8]$. 
The most common radiographic feature is multiple lung nodules, which can be seen in $80 \%$ of cases. As these lesions can rapidly progress and cavitate, PLG often resembles granulomatosis with polyangiitis (Wegener's) or metastases [3]. These nodules can disappear or migrate spontaneously and display the "reversed halo" sign, with a central ground glass opacity surrounded by denser consolidation [3]. Pleural effusions have been seen in $25 \%$ of cases and mediastinal lymphadenopathy is visible on CT in $60 \%$ of patients [9].

Other radiological appearances seen less commonly include coarse linear opacities along the bronchovascular bundles and thin-walled cysts [3].

Other manifestations of PLG in the literature include a large necrotic tumor in the left upper lobe [10], idiopathic interstitial pneumonia [2], a solitary lung nodule [11] or mass [12, 13], and a lung abscess [14].

The only case similar to ours showed a chest X-ray with a mass inferior to the right hilum [15]. To the best of our knowledge, an isolated hilar mass such as in our patient is a highly peculiar and unusual manifestation of PLG.

The prognosis for PLG is variable, with a corelation with histological grade [4]. $20 \%$ of Stage 1 patients can achieve spontaneous remission [4], but the course of PLG can be fulminant. Studies have shown a median survival of 14 months and a mortality of $65-90 \%$, with death resulting from various causes: pulmonary complications, severe neurological disease, or complications of therapy [16].

Management of this condition should be an individualized decision based on the patient's characteristics. Low-grade tumors can be managed expectantly; however, symptomatic or higher grade patients should be considered for chemotherapy $[1,4]$.

Generally treatment options for PLG are similar to that of diffuse large B-cell lymphoma [1, 4, 17].

Although this is not a common differential for a hilar mass, the possibility of rarer diseases should also be considered in the differentials, as was evident in our patient.

\section{Disclosure}

This is to confirm that there is no known conflict of interests associated with this publication. There has been no financial support for this work that can possibly influence its outcome. The authors confirm that the paper has been read and approved by all named authors. The order of authors listed in the paper has been approved by all of the authors. Due consideration has been given to the protection of intellectual property associated with this work. The authors confirm that they have followed the regulations of their institutions relating to intellectual property.

\section{References}

[1] S. Pittaluga, S. W. W, and E. S. Jaffe, World Health Organization Classification of Tumors of Hematopoetic and Lymphoid Tissues, IARC Press, Lyon, France, 2008.

[2] A. Makol, K. Kosuri, D. Tamkus, W. De M Calaca, and H. T. Chang, "Lymphomatoid granulomatosis masquerading as interstitial pneumonia in a 66-year-old man: a case report and review of literature," Journal of Hematology and Oncology, vol. 2, p. 39, 2009.

[3] S. S. Hare, C. A. Souza, G. Bain et al., "The radiological spectrum of pulmonary lymphoproliferative disease," British Journal of Radiology, vol. 85, no. 1015, pp. 848-864, 2012.

[4] E. S. Jaffe and W. H. Wilson, "Lymphomatoid granulomatosis: pathogenesis, pathology and clinical implications," Cancer Surveys, vol. 30, pp. 233-248, 1997.

[5] R. Joseph, B. Chacko, M. T. Manipadam, J. Sureka, V. K. Cherian, and G. T. John, "Pulmonary lymphomatoid granulomatosis in a renal allograft recipient," Transplant Infectious Disease, vol. 10, no. 1, pp. 52-55, 2008.

[6] R. J. Pisani and R. DeRemee, "Clinical implications of the histopathologic diagnosis of pulmonary lymphomatoid granulomatosis," Mayo Clinic Proceedings, vol. 65, no. 2, pp. 151-163, 1990.

[7] A. L. A. Katzenstein, C. B. Carrington, and A. A. Liebow, "Lymphomatoid granulomatosis. A clinicopathologic study of 152 cases," Cancer, vol. 43, no. 1, pp. 360-373, 1979.

[8] T. Mizuno, Y. Takanashi, H. Onodera et al., "A case of lymphomatoid granulomatosis/angiocentric immunoproliferative lesion with long clinical course and diffuse brain involvement," Journal of the Neurological Sciences, vol. 213, no. 1-2, pp. 6776, 2003.

[9] B. Vahid, D. A. Salerno, and P. E. Marik, "Lymphomatoid granulomatosis: a rare cause of multiple pulmonary nodules," Respiratory Care, vol. 53, no. 9, pp. 1227-1229, 2008.

[10] W. Bartosik, A. Raza, S. Kalimuthu, and A. Fabre, "Pulmonary lymphomatoid granulomatosis mimicking lung cancer," Interactive CardioVasc Thoracic Surgery, vol. 14, no. 5, pp. 662-664, 2012.

[11] T. Itoh, K. Umekawa, K. Rensha et al., "A case of grade I lymphomatoid granulomatosis detected as a solitary lung nodule in a health examination," Nihon Kokyuki Gakkai Zasshi, vol. 46, no. 1 , pp. 50-54, 2008.

[12] P. S. Koh, A. H. C. Foyle, Y. Cartier et al., "Atypical presentation of lymphomatoid granulomatosis in a patient with longstanding sarcoidosis," Canadian Respiratory Journal, vol. 11, no. 1, pp. 51-54, 2004.

[13] F. Lou and Z. Xing, "Clinicopathologic conference. A 48-yearold woman with large mass shadow in the right lower lung with cough, chest pain and fever," Chinese Medical Journal, vol. 101, no. 9, pp. 695-699, 1988.

[14] M. McCloskey, M. Catherwood, D. McManus, G. Todd, R. Cuthbert, and M. Riley, "A case of lymphomatoid granulomatosis masquerading as a lung abscess," Thorax, vol. 59, no. 9, pp. 818-819, 2004.

[15] Y. Paramsothy, A. Ilchyshyn, K. Sidky, and J. P. H. Byrne, "Lymphomatoid granulomatosis mimicking bronchial carcinoma," Postgraduate Medical Journal, vol. 63, no. 739, pp. 381384, 1987.

[16] N. Sheehy, B. Bird, D. S. O’Briain, P. Daly, and G. Wilson, "Synchronous regression and progression of pulmonary nodules on chest CT in untreated lymphomatoid granulomatosis," Clinical Radiology, vol. 59, no. 5, pp. 451-454, 2004.

[17] W. H. Wilson, D. W. Kingma, M. Raffeld, R. E. Wittes, and E. S. Jaffe, "Association of lymphomatoid granulomatosis with Epstein-Barr viral infection of B lymphocytes and response to interferon- $\alpha 2$ b," Blood, vol. 87, no. 11, pp. 4531-4537, 1996. 


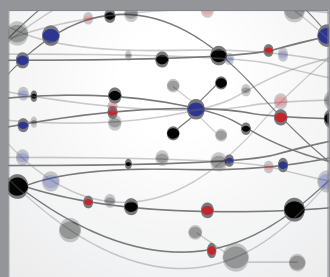

The Scientific World Journal
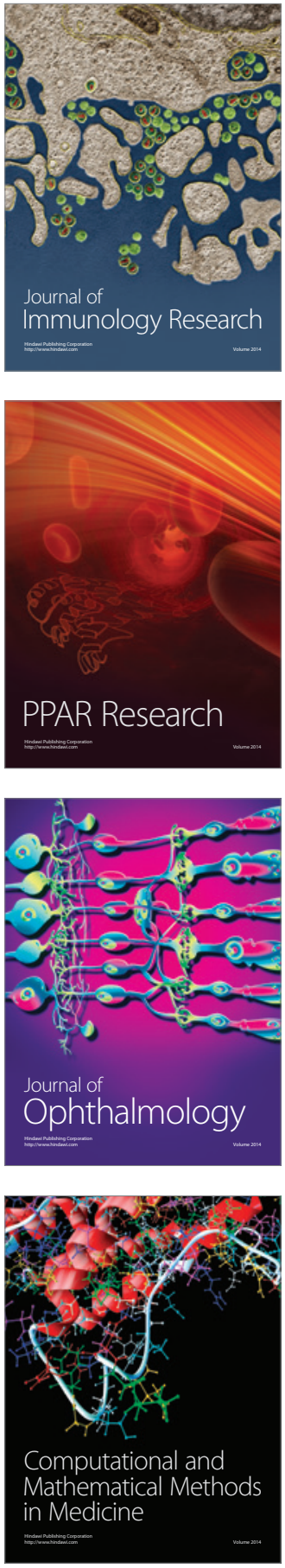

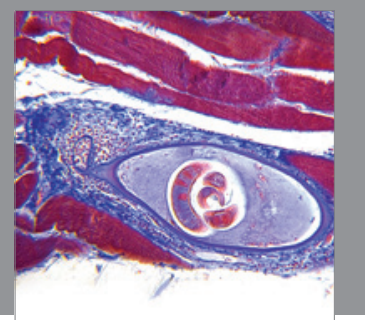

Gastroenterology

Research and Practice
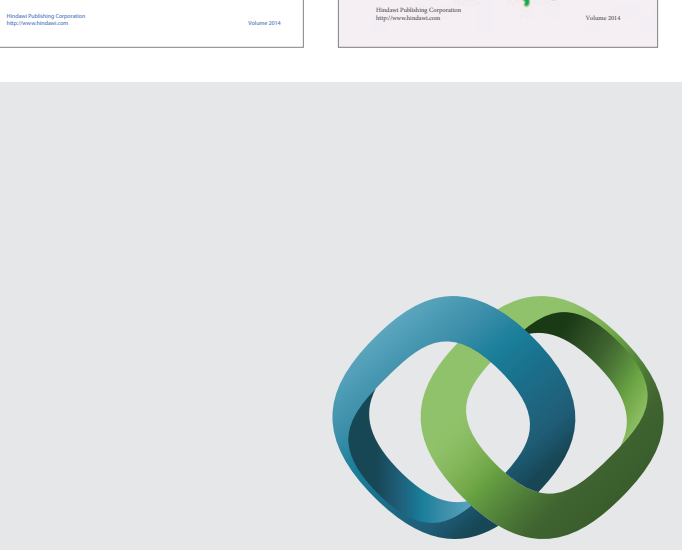

\section{Hindawi}

Submit your manuscripts at

http://www.hindawi.com
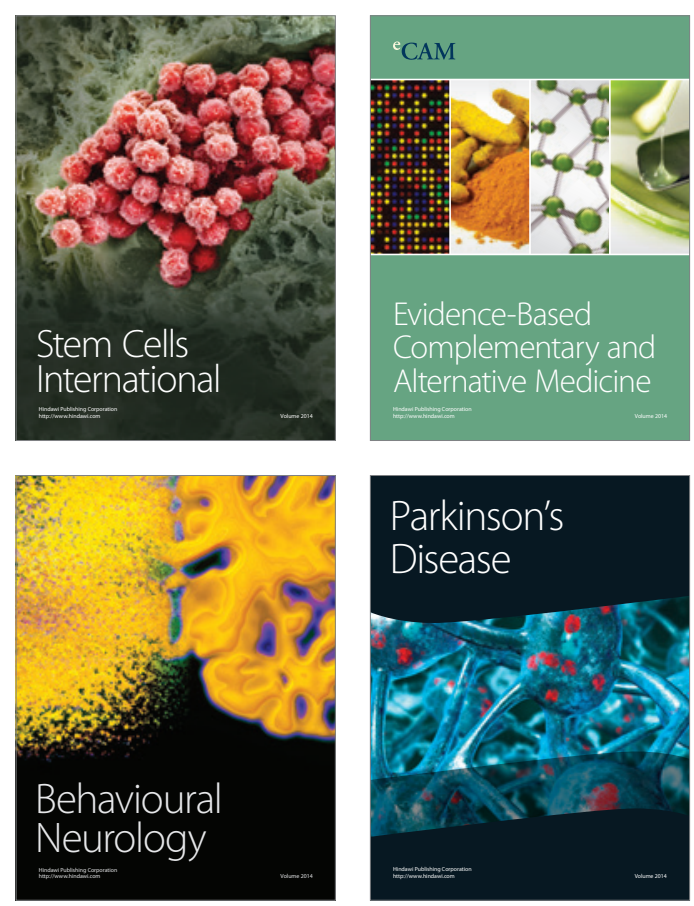

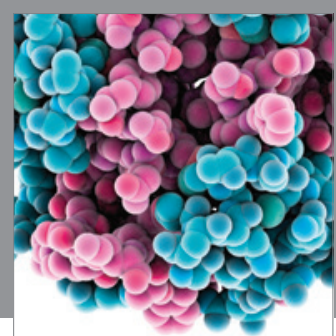

Journal of
Diabetes Research

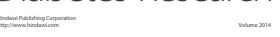

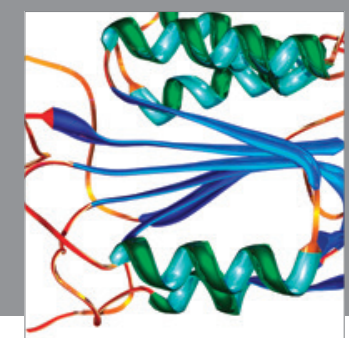

Disease Markers
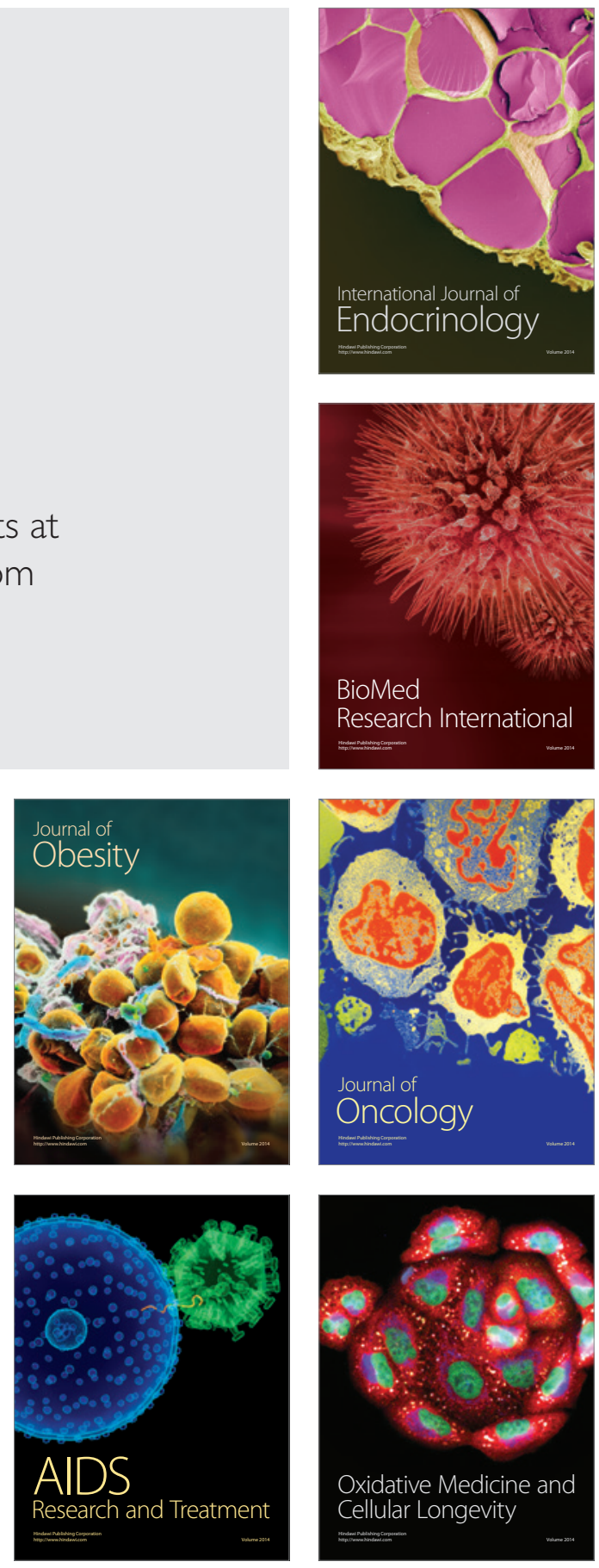